\title{
Dinâmica de Aprendizagem: a relaçÃo entre processos, CONTEÚDO TRANSACIONADO E CONFIGURAÇÃO DA REDE EM UMA ORGANIZAÇÃO NÃO GOVERNAMENTAL
}

\author{
Dynamic of Learning: the relationship between process, \\ transacted content and configuration of the network in a non- \\ governmental organization
}

\section{Catarina Cecília Odelius}

Professora Associada do Programa de Pós-Graduação em Administração. Universidade de Brasília (UnB). Brasília, DF. Brasil.

E-mail:codelius@unb.br

André de Castro Sena.

Coordenador de Almoxarifado e Patrimônio. Instituto Federal de Brasília (IFB). Campus Estrutural. Brasília, DF. Brasil.

E-mail: andrecsena@gmail.com

\section{Resumo}

As redes de aprendizagem em uma organização não governamental foram caracterizadas quanto a conteúdos transacionados e processos de aprendizagem. Pesquisa documental e 16 entrevistas forneceram dados que resultaram em 573 conteúdos aprendidos, categorizados, a posteriori, em: comportamentos associados ao ambiente organizacional (fundamentose visão da organização, comportamento para o trabalho e relacionamento com atores externos); conhecimentos e habilidades relativos ao trabalho; e desenvolvimento individual. As redes relativas ao ambiente organizacional também estão descritas neste artigo. Entre os processos de aprendizagem identificados encontram-se: atividade, convivência, ensinar, feedback, material, observação e supervisão. As redes de aprendizagem foram analisadas a partir de seus aspectos estruturais, conteúdos transacionados e processos utilizados. A aprendizagem foi identificada como fruto de relações dinâmicas estabelecidas entre diversos atores, em situações delimitadas por ações cotidianas e condições impostas pelo contexto. Certos processos de aprendizagem foram mais recorrentes ou funcionaram melhor do que outros, dependendo do conteúdo aprendido ou das preferências e características dos indivíduos.

Palavras-chave: Aprendizagem em Organizações. Processos de Aprendizagem. Redes Sociais. Teoria de Rede de Aprendizagem. Organizações Não Governamentais.

\section{Abstract}

Learning networks in a non-governmental organization were characterized and analysed by the learning contents and the processes by which they were learned. Data were collected by means of document research and 16 interviews; and 573 learning contents were identified and classified into the following categories: organizational environment-related behaviors (organizational environment, work behaviors and relations with external actors), work-related knowledge and skills, and individual development. In this article only the organizational environment networks are described. Learning processes identified included activities, getting along with others, teaching, feedback, material, observation and supervision. Learning networks were analyzed with respect to their structural characteristics, contents transacted and the learning processes employed. Learning was found to result from the dynamic relationships established among different actors while going about their routine activities and dealing with the conditions imposed by the internal and external environment. Some learning processes are more recurrent or work better than others, depending upon the content learned or preferences and characteristics of individuals.

Keywords: Learning in Organizations. Learning process. Social Networks. Learning Network Theory. Non-Governamental Organization. 


\section{INTRODUÇÃO}

As Organizações Não Governamentais (ONGs) possuem uma identidade organizacional relativamente recente, elas se constituem e se vocacionam a papéis e finalidades diferenciados de outras organizações (TORO, 2000); atuam de modo peculiar, tendo sua dinâmica tanto interna quanto externa permeada pela participação de voluntários, cujo recrutamento e gerenciamento constituem-se em processos com complexidade, dilemas e ambiguidades próprias (TEODÓSIO; VENEROSO; PENA, 2006); apresentam práticas de gestão de pessoas que se figuram ora como soluções criativas e inovadoras, ora como obstáculos à adoção de sistemas administrativos mais estruturados (BOSE, 2000); não veem o recurso financeiro como uma finalidade da organização e sim como um meio para operacionalização de sua missão, o que diferencia, mas não diminui nem a importância do dinheiro nem a necessidade de se desenvolver estratégias para obtê-lo em consonância com os valores da organização. (CAMARGO et al., 2001)

Em face ao exposto, pode-se dizer que as ONGs apresentam especificidades e peculiaridades relativas à estrutura e à dinâmica organizacional, que as distinguem de outras organizações e que, portanto, demandam a realização de pesquisas que permitam compreender esses fenômenos organizacionais.

Durante a década de 1990, quando padrões de excelência para os resultados das ações de ONGs começaram a ser amplamente discutidos, um estudo de Edwards e Hulme (1995) constatou que o impacto das ações de uma ONG, sua capacidade de atrair financiamento e sua legitimidade, como o ator do desenvolvimento territorial, ficarão mais evidentes quanto maior for sua habilidade em demonstrar que é capaz de ter uma performance efetiva e de assumir plena responsabilidade por suas ações. Nesse contexto, a gestão do conhecimento e a aprendizagem organizacional surgiram como temas prementes para pesquisadores e administradores dessas organizações.

Em relação à aprendizagem em organizações, o conhecimento acumulado indica que o aprendizado é decorrente de: processos formais e informais; características e interesses dos indivíduos; e influências recebidas do contexto - ambiente, liderança, recursos, tempo, materiais, políticas e programas organizacionais
(MARSICK, 2009). Os indivíduos têm papel ativo no processo de aprendizagem, e, quando se trata da aprendizagem informal, essa aprendizagem pode ocorrer a partir de escolhas conscientes dos indivíduos, ou de modo tácito, sem que haja um conhecimento a respeito do que ou como o aprendizado ocorreu.

Poell et al. (2000), buscando apresentar um modelo de análise para a aprendizagem organizacional, propõem a Teoria de Rede de Aprendizagem, que engloba a atuação dos indivíduos, estruturas e processos organizacionais. Esses autores destacam que a rede de aprendizagem não tem relação com as redes sociais ou interorganizacionais, porém, considerando que a análise das redes sociais pode contribuir para explicitar as relações que se estabelecem a partir de conteúdos transacionados em processos de aprendizagem, o objetivo deste estudo é identificar as redes de aprendizagem estabelecidas, entre 2007 e 2008, em uma organização não governamental, caracterizando-as quanto a conteúdos transacionados e processos de aprendizagem.

Integram este artigo, além da introdução, a base teórica que fundamenta o estudo e que abrange a aprendizagem organizacional e a Teoria de Redes de Aprendizagem (TRA), o método utilizado para o desenvolvimento do estudo, os resultados organizados em conteúdos aprendidos, processos de aprendizagem e redes de aprendizagem, com a sua respectiva discussão, $e$ as considerações finais.

\section{Aprendizagem Organizacional e Redes Sociais de Aprendizagem}

Entre os pesquisadores que estudam a aprendizagem organizacional há um consenso em considerar que dizer que uma organização aprende nada mais é que fazer uso de uma metáfora derivada do entendimento que se tem do que seja a aprendizagem individual (KIM, 1993). Em última análise, o fenômeno que se está observando, ao se dizer que uma organização aprende, necessariamente ocorre devido à aprendizagem dos indivíduos que a compõem. Condição necessária, mas não suficiente, uma vez que a aprendizagem organizacional não pode ser simplesmente resumida à soma das aprendizagens de seus membros. (FIOL; LYLES, 1985; SWIERINGA; WIERDSMAN, 1992) 
É preciso compreender como o indivíduo aprende em um contexto onde esse aprendizado é parte de um sistema de consequências mais complexas, o qual é chamado de aprendizagem organizacional. Uma das maneiras estudadas pela qual a aprendizagem organizacional pode ocorrer diz respeito às trocas entre os membros da organização (ARGOTE et al., 2000), havendo evidências de que boa parte dos conteúdos aprendidos vêm de (ou são influenciados por) interações didáticas (BAILEY; BARLEY, 2006). A aprendizagem, além de ser uma atividade individual e um processo cognitivo, é também um processo social, sobre o qual a estrutura organizacional tem uma função mediadora fundamental, pois delimita as situações em que informações são transmitidas de um membro a outro.

Partindo da perspectiva de redes, em um modelo que sintetizasse as metáforas da aquisição e da participação na abordagem ao fenômeno da aprendizagem organizacional, Van Der Krogt (1995) desenvolveu a Teoria de Redes de Aprendizagem (TRA), a qual descreve como a aprendizagem é organizada no contexto de organizações de trabalho. Segundo a teoria, a rede de aprendizagem representa como a aprendizagem é estruturada e composta de várias atividades de aprendizagem organizadas pelos membros da organização. O modelo descritivo-interpretativo apresentado por essa teoria possui três componentes básicos: atores (com suas teorias de ação de aprendizagem), estruturas de aprendizagem (conteúdos, estruturas organizacionais e clima) e processos de aprendizagem (políticas, programas e trilhas). (POELL et al., 2000)

Elemento central das redes de aprendizagem, os atores são indivíduos engajados na organização da aprendizagem, podendo ser internos (membros da organização) ou externos (indivíduos/instituições relacionados com as atividades da organização). Possuem um conjunto de valores, conhecimentos e habilidades que lhes possibilita interpretar situações e agir apropriadamente - as chamadas teorias de ação. As teorias de ação de um indivíduo relativas aos processos que envolvem sistemas de aprendizagem podem ser descritas como a configuração de princípios, discernimentos, regras, ações e efeitos que direcionam ao mesmo tempo as interpretações que os atores têm do sistema de aprendizagem e suas ações no âmbito desse sistema. (VAN DER KROGT, 1998)
Aprender na perspectiva da teoria de redes de aprendizagem implica em o indivíduo desenvolver as suas próprias teorias a respeito da aprendizagem. Os atores percebem e interpretam seu contexto, se engajam em atividades de aprendizagem de acordo com suas próprias ideias - implícitas ou explícitas - quanto ao que e como deveriam aprender e, em função de interesses de aprendizagem comuns, formam grupos - formais ou informais - de aprendizagem focados na realização de atividades específicas.

As interações entre os atores para organizar atividades de aprendizagem demandam três processos: desenvolvimento de políticas de aprendizagem, organização de programas de aprendizagem e criação de trilhas de aprendizagem. (POELL; VAN DER KROGT, 2007)

O desenvolvimento de políticas de aprendizagem refere-se a atividades que influenciam o direcionamento mais amplo da rede de aprendizagem, isto é, o entendimento a respeito do que os membros da organização deveriam aprender e de que maneiras deveriam aprendê-lo. Atividades nesse processo incluem, entre outras, refletir a respeito de necessidades de aprendizagem, discutir as consequências de inovações no trabalho, listar competências disponíveis e desejáveis.

A depender das características da rede de aprendizagem, as políticas podem não ser definidas a priori (sendo desenvolvidas por meio do aprendizado pela experiência, à medida que os programas de aprendizagem vão sendo executados), podem ser inspiradas por novidades surgidas especificamente na profissão dos empregados (influência de associações profissionais), podem permanecer implícitas (pelo menos do ponto de vista da organização) ou podem ser desenvolvidas pela gerência (em um procedimento de planejamento linear das atividades de aprendizagem a serem desempenhadas pelos empregados). (POELL, 1998)

A criação de programas de aprendizagem, que correspondem à criação de oportunidades de aprendizagem e a combinação de várias atividades de aprendizagem em programas mais ou menos coerentes, assim como a definição de trilhas de aprendizagem do ponto de vista do ator da rede, ou seja, do indivíduo, integram a TRA (POELL; VAN DER KROGT, 2003). Entre os atores da aprendizagem envolvidos nessa criação estão tanto os educadores e treinadores - oriundos ou contratados por departamentos de recursos humanos/gestão 
de pessoas, quanto os próprios empregados e gerentes. A aprendizagem em situações cotidianas de trabalho emerge de eventos sociais, em encontros promovidos para os membros da equipe de trabalho ou em reunióes para tratar de temas específicos e pode ser induzida de maneira mais sistemática e explícita, e variar no que se refere à estruturação, complexidade, deliberação $e$ participação. Todos os programas de aprendizagem necessariamente envolvem atividades informais no contexto de trabalho, mas podem incluir também algum tipo de atividade de treinamento formal.

A teoria de redes de aprendizagem define uma trilha de aprendizagem do ponto de vista do ator da rede, ou seja, do indivíduo. O conceito se refere a um conjunto de atividades de aprendizagem, essas aprendizagens têm uma coerência entre si e são significativas para o membro da organização. (POELL; VAN DER KROGT, 2007)

As estruturas de aprendizagem são padrões estáveis de interação que tendem a se desenvolver quando as pessoas interagem organizando a aprendizagem por um longo período de tempo. Pode-se observar, em certas estruturas de conteúdo, estruturas organizacionais no clima para a aprendizagem.

As estruturas organizacionais constituem as regras e regulamentos envolvidos no desenvolvimento e na implementação das várias atividades de aprendizagem, além da divisão de tarefas e responsabilidades entre os vários atores no sistema de aprendizagem, o que envolve estruturas de comunicação e consulta (POELL; VAN DER KROGT, 2007). Já o clima para a aprendizagem é definido como: normas e valores a respeito da aprendizagem e sua organização, expressos por meio das ações dos atores, e que determinam os tipos de relações que se estabelecem na rede. (POELL; MOORSEL, 1996)

\section{Método}

O estudo é caracterizado como documental, exploratório, descritivo e de campo. A organização foi escolhida por acessibilidade e conveniência e se autodenomina um grupo de pesquisa e experimentação em mídias de acesso público. É uma associação legalmente constituída cujo foco de atuação se dá nas áreas de comunicação comunitária e educação midiática, desen- volvendo processos formativos e pesquisas, realizando produções em variadas mídias e prestando consultorias voltadas para a inclusão de diversos segmentos sociais no universo de produção e uso das comunicações $e$ novas tecnologias da informação. ${ }^{1}$

A população investigada foi o conjunto dos membros envolvidos nas atividades da ONG durante a integralidade do biênio 2007-2008, resultando em 20 pessoas que atendiam ao critério estabelecido, sendo que dessas, 16 foram entrevistadas. Quatro pessoas não foram entrevistadas por dificuldades de conciliação de agendas e questões logísticas.

Dos 16 entrevistados, nove são homens e sete são mulheres, com idades entre 20 e 35 anos. Nove tinham nível superior completo, cinco cursavam faculdade, um havia terminado o ensino médio e um ainda o estava cursando.

Os dados foram levantados por meio de pesquisa documental e entrevistas semiestruturadas, tendo sido pedido que relatassem quais eram as pessoas mais importantes para o desempenho de suas funções naquele período, o que aprenderam com essas pessoas e por meio de que processos.

Foram depreendidas 573 ocorrências de conteúdos aprendidos, organizadas, a posteriori, em três grupos e 11 categorias, que correspondem às redes de aprendizagem na organização: 1) comportamentos associados ao ambiente organizacional (Fundamentação e Visão da organização, Comportamento para o trabalho; Relacionamento com atores externos); 2) conhecimentos e habilidades necessários à realização do trabalho (Técnica; Gestão; Condução de oficina; Projeto); e 3) desenvolvimento individual (Referência pessoal; Artes \& cultura; Estímulo ao próprio desenvolvimento).

Os processos de aprendizagem que permitiram a apropriação dos conteúdos foram agrupados em nove categorias: Apropriação, Atividade, Convivência, Ensinar, Feedback, Material, Observação, Sugestão/ indução e Supervisão.

As redes foram descritas e analisadas quanto a: 1) aspectos estruturais (quantidade de relações efetivas e de atores, distância geodésica média, diâmetro, densidade, cutpoints, relações recíprocas, quantidade de relações por ator); e 2) conteúdos transacionados nas relações e processos de aprendizagem utilizados. Quanto aos aspectos estruturais, para cada rede foram 
calculados, por meio do programa Ucinet 6 for Windows: quantidade de relações efetivas (“[...] quantidade total de relações existentes na rede, estabelecidas entre pares de atores. (WASSERMAN; FAUST, 1994, p. 20), quantidade de atores ${ }^{2}$, distância geodésica média ${ }^{3}$, diâmetro ${ }^{4}$, densidade $e^{5}$, cutpoints 6 , relações recíprocas ${ }^{7}$, quantidade de relações por ator (total, quantidade de relações em que ensina, quantidade de relações em que aprende). Foi gerado também um gráfico para cada uma das redes de aprendizagem, utilizando-se o programa NetDraw 2.092.

Além dos 16 entrevistados, foram citadas nas entrevistas outras vinte e seis pessoas, com quem os entrevistados aprenderam durante o período delimitado para a pesquisa, num total de quarenta e duas pessoas mencionadas. Para a análise dos dados foi utilizada a codificação ENT, para os entrevistados $e$ CIT, para os citados, seguido de números, que indicam diferentes sujeitos.

Os documentos da organização contribuíram para a contextualização e compreensão das redes de aprendizagem e dos processos que as constituíram.

Nesse relato estão apresentadas as redes de aprendizagem relativas a comportamentos associados ao ambiente organizacional. Esta delimitação se deve ao limite de espaço para apresentação dos dados e à importância dessas redes.

Como limitação ao trabalho realizado, encontra-se o pouco poder de generalização dos resultados encontrados para outras organizações, visto se tratar de um estudo circunscrito a uma única organização $e$ as entrevistas terem sido realizadas no segundo semestre de 2009 a respeito de fatos ocorridos nos anos de 2007 e 2008. A distância temporal pode enviesar as respostas de entrevistados por depender muito da maneira como cada um individualmente se lembra dos fatos ocorridos e os relata.

Isso posto, os achados relatados e discutidos não exaurem as possibilidades de compreensão das características das relações existentes entre aprendizagem em organizações e redes sociais, quanto a conteúdos transacionados e processos de aprendizagem, em organizações não governamentais.

\section{Redes de Aprendizagem, Conteúdos Aprendidos e Processos de Aprendizagem}

Os resultados estão organizados da seguinte maneira: inicialmente estão apresentados os grupos de conteúdos aprendidos e os processos de aprendizagem identificados, com as respectivas definições de cada categoria, seguidas dos dados relativos às redes de aprendizagem.

O conjunto de dados relativos às relações estabelecidas entre os pesquisados, os conteúdos aprendidos e os processos de aprendizagem, que possibilitou a identificação das redes de aprendizagem, estará analisado juntamente com as redes, mais adiante.

Os dados relativos: 1) aos comportamentos associados ao ambiente organizacional (Fundamentação e Visão da organização, Comportamento para o trabalho; Relacionamento com atores externos); e 2) aos conhecimentos e habilidades necessários à realização do trabalho (Gestão; Técnica; Condução de oficina; Projeto) estão apresentados nas Tabelas 1 e 2 .

Os conteúdos aprendidos mais citados nas entrevistas foram os relativos a comportamentos associados ao ambiente organizacional (280) e aos conhecimentos e habilidades necessários à realização do trabalho (216), sendo que as categorias com maior número de conteúdos aprendidos foram comportamentos para o trabalho (168) (citada por todos os entrevistados) e Técnica (101).

Os conteúdos associados ao desenvolvimento individual não eram esperados no processo de coleta de dados, uma vez que foi solicitado que os entrevistados abordassem conteúdos aprendidos no trabalho, porém considerando a pertinência desses dados no contexto da Teoria de Redes de Aprendizagem, estão apresentados na Tabela 2 . 
Tabela 1: Conteúdos aprendidos por categoria

\begin{tabular}{|c|c|c|c|c|}
\hline Categoria & DefinIÇÃo & (A) & $\begin{array}{l}\% \\
(\text { в) }\end{array}$ & (c) \\
\hline Fundamentação & $\begin{array}{l}\text { É relativa ao aprendizado de conceitos norteadores das práticas organizacionais, criação } \\
\text { de métodos, assim como de discussões, reflexões e teorizações relativas ao dia a dia da } \\
\text { organização. }\end{array}$ & 57 & 10 & 13 \\
\hline $\begin{array}{l}\text { Visão da } \\
\text { organização }\end{array}$ & $\begin{array}{l}\text { Agrupa ocorrências de aprendizados relacionados aos valores organizacionais, } \\
\text { funcionamento, estrutura, dinâmica de relacionamento entre os departamentos, abrangência } \\
\text { de atuação, impactos e sustentabilidade da organização. }\end{array}$ & 16 & 3 & 7 \\
\hline $\begin{array}{l}\text { Comportamento } \\
\text { para o trabalho }\end{array}$ & $\begin{array}{l}\text { Abrange o aprendizado de comportamentos pertinentes ao convívio no grupo e ao } \\
\text { desenvolvimento das atribuições dos entrevistados: relacionamento interpessoal, } \\
\text { comunicação, postura profissional, padrões para o desenvolvimento do trabalho e ética. }\end{array}$ & 168 & 29 & 16 \\
\hline $\begin{array}{l}\text { Relacionamento } \\
\text { com atores externos }\end{array}$ & $\begin{array}{l}\text { Abrange aprendizados relacionados à comunicação externa, relacionamento com } \\
\text { patrocinadores, comunidades, público-alvo e fornecedores, ou seja, o relacionamento com } \\
\text { outras instituições e indivíduos não integrantes da organização pesquisada, que possuem } \\
\text { interesses, prioridades, ritmos e lógicas de funcionamento diferentes, o que demanda } \\
\text { daqueles que estabelecem esse contato o desenvolvimento de estratégias e competências } \\
\text { específicas. }\end{array}$ & 39 & 7 & 12 \\
\hline Subtotal & Conteúdos associados ao ambiente organizacional. & 280 & 49 & \\
\hline Gestão & $\begin{array}{l}\text { Está relacionado à ocorrência de aprendizados relativos às funções gerenciais: planejamento, } \\
\text { organização, direção e controle. }\end{array}$ & 64 & 11 & 12 \\
\hline Técnica & $\begin{array}{l}\text { Agrupa os aprendizados relacionados diretamente à elaboração e execução de produtos } \\
\text { midiáticos. }\end{array}$ & 101 & 18 & 14 \\
\hline Condução de oficina & $\begin{array}{l}\text { Abrange aprendizados relacionados especificamente e exclusivamente ao trabalho relativo } \\
\text { a oficinas: abordagens pedagógicas, elaboração de propostas, formas de execução, atitudes } \\
\text { e habilidades sociais especificamente relacionadas à atividade. }\end{array}$ & 26 & 5 & 11 \\
\hline Projeto & Inclui a aprendizagem de atividades de elaboração, gestão e execução de projetos. & 25 & 4 & 11 \\
\hline Subtotal & $\begin{array}{l}\text { Conteúdos aprendidos associados a conhecimentos e habilidades necessários à realização } \\
\text { do trabalho. }\end{array}$ & 216 & 38 & \\
\hline Total & & 496 & 87 & \\
\hline
\end{tabular}

Nota: (a) número de ocorrências; (b) \% considerando o total de 573 ocorrências; (c) número de entrevistas em que apareceu (máximo 16)

Fonte: Dados da pesquisa

Tabela 2: Ocorrências de conteúdos aprendidos associados a desenvolvimento individual, por categoria

CATEGORIA

DEFINIÇÃo
(A) $\%$

Está relacionado a aprendizados surgidos a partir de comportamentos exemplares dos colegas testemunhados ou vividos para consigo - ensinamentos de valores e procedimentos que, apesar de em alguns casos serem úteis para atividades desempenhadas no trabalho, foram relatados pelo entrevistado em alusão direta a atividades e interesses relacionados à sua vida particular.

Foram agrupadas ocorrências de aprendizados de conhecimentos e habilidades do campo das artes e cultura que foram abordados em um contexto associado a atividades e interesses que concernem especificamente à vida particular do indivíduo, podendo, eventualmente serem úteis em atividades desempenhadas no trabalho.

Estímulo ao próprio desenvolvimento

Abrange os aprendizados sobre si mesmos que levaram a um desenvolvimento do ponto de vista profissional, induzidos por comportamentos dos colegas (superiores ou pares).

Total

\begin{tabular}{|l|l|l|}
\hline 37 & 6 & 11 \\
\hline & & \\
\hline 11 & 2 & 7 \\
\hline 77 & 13 & \\
\hline
\end{tabular}

Nota. (a) número de ocorrências; (b) \% considerando o total de 573 ocorrências; (c) número de entrevistas em que apareceu (máximo 16) Fonte: Dados da pesquisa 
Uma vez identificados os conteúdos aprendidos, passou-se à análise dos processos de aprendizagem por meio dos quais os entrevistados alegaram haver aprendido. Em 61 das 573 ocorrências (11\%) os en- trevistados não especificaram o modo como o aprendizado ocorreu. Os processos depreendidos das demais respostas e as respectivas definições estão apresentados na Tabela 3.

Tabela 3: Processos de aprendizagem por categoria

\begin{tabular}{|c|c|c|c|c|}
\hline CATEgoria & DEFINIÇÃo & (A) & $\begin{array}{l}\% \\
\text { (в) }\end{array}$ & (c) \\
\hline Observação & $\begin{array}{l}\text { O aprendizado é fruto do testemunho de uma atividade desenvolvida pelo colega em paralelo } \\
\text { à do entrevistado }\end{array}$ & 92 & 16 & 16 \\
\hline Ensinar & $\begin{array}{l}\text { Situação em que o colega age com o objetivo deliberado de ensinar conceitos ou práticas. } \\
\text { Pressupõe que o colega saiba um pouco mais que o entrevistado sobre o assunto ensinado, } \\
\text { estabelecendo uma relação assimétrica de ensino-aprendizagem. }\end{array}$ & 89 & 16 & 15 \\
\hline Convivência & $\begin{array}{l}\text { Aprendizado que ocorre como consequência da convivência cotidiana, não se dando de forma } \\
\text { pontual e sim processual - o que difere "convivência" de outras categorias. }\end{array}$ & 72 & 13 & 13 \\
\hline Atividade & $\begin{array}{l}\text { Aprendizado decorrente de execução de atividade junto com o colega. Ocorre quando os dois } \\
\text { estão incumbidos de uma mesma tarefa, em um mesmo nível hierárquico. }\end{array}$ & 66 & 12 & 14 \\
\hline Feedback & $\begin{array}{l}\text { Aprendizado decorrente de comentários feitos pelo colega, que levam à reflexão e à autocrítica. } \\
\text { O posicionamento do colega ao qual é atribuído um aprendizado trata sempre de um evento } \\
\text { ocorrido no passado. }\end{array}$ & 46 & 8 & 13 \\
\hline Supervisão & $\begin{array}{l}\text { Aprendizado decorrente de execução de atividade sob a supervisão do colega. Ocorre } \\
\text { quando os dois estão incumbidos de uma tarefa, sendo que o colega encontra-se em um } \\
\text { nível hierárquico superior. }\end{array}$ & 43 & 8 & 10 \\
\hline Material & $\begin{array}{l}\text { Aprendizado decorrente de referências recomendadas/trocadas/passadas pelo colega (leituras, } \\
\text { filmes, músicas e objetos culturais em geral). }\end{array}$ & 39 & 7 & 12 \\
\hline Apropriação & $\begin{array}{l}\text { Aprendizado decorrente da reprodução de maneiras pelas quais o colega procede em } \\
\text { determinadas situações. Ocorre quando o colega tem uma maneira já estabelecida de } \\
\text { proceder da qual o entrevistado toma conhecimento e cópia, não necessariamente tendo-a } \\
\text { testemunhado. }\end{array}$ & 33 & 6 & 13 \\
\hline $\begin{array}{l}\text { Sugestão/ } \\
\text { indução }\end{array}$ & $\begin{array}{l}\text { Aprendizado decorrente de sugestões do colega quanto a modos de executar uma atividade, } \\
\text { comportamentos a se adotar em determinadas situações ou ainda aprendizado resultante do } \\
\text { engajamento - induzido pelo colega - em determinada ação. }\end{array}$ & 32 & 6 & 11 \\
\hline $\begin{array}{l}\text { Não } \\
\text { especificado }\end{array}$ & Não foi explicitado o processo de aprendizagem. & 61 & 11 & 12 \\
\hline Total & & 573 & 100 & \\
\hline
\end{tabular}

Nota. (a) número de ocorrências; (b) \% considerando o total de 573 ocorrências; (c) número de entrevistas em que apareceu (máximo 16) Fonte: Dados da pesquisa

\subsection{Redes de Aprendizagem}

Os aspectos estruturais das redes estão apresentados na Tabela 4 e os resultados estão analisados nos tópicos relativos a cada rede. 
Tabela 4: Aspectos estruturais das redes de aprendizagem identificadas

\begin{tabular}{|c|c|c|c|c|c|c|c|}
\hline REDE & $\begin{array}{c}\text { QTDE. DE } \\
\text { RELAÇÕES EFETIVAS }\end{array}$ & $\begin{array}{c}\text { QTDE. } \\
\text { DE } \\
\text { ATORES }\end{array}$ & $\begin{array}{c}\text { DisTÂNCIA } \\
\text { GEODÉSICA MÉDIA }\end{array}$ & DiÂMETRO & Densidade & $\begin{array}{c}\text { Cut- } \\
\text { POINTS }\end{array}$ & $\begin{array}{l}\text { RELAÇÕES } \\
\text { RECÍPROCAS }\end{array}$ \\
\hline Fundamentação & 27 & 21 & 1,79 & 3 & $6,4 \%$ & 5 & 2 \\
\hline Comportamento & 100 & 33 & 2,47 & 5 & $9,5 \%$ & 8 & 14 \\
\hline Relacionamento & 28 & 21 & 2,23 & 3 & $7,0 \%$ & 5 & 1 \\
\hline
\end{tabular}

Fonte: Dados da pesquisa

\subsubsection{Rede de Aprendizagem - Fundamentação}

A rede Fundamentação, apresentada na Figura 1 , conta com a participação de 21 atores e tem 27 relações efetivas, nas quais foram transacionados 57 conteúdos. Possui uma distância geodésica média de 1,79 . Seu diâmetro e densidade (3 e 6,4 \%, respectivamente) também ficaram abaixo da média das redes (3,9 e 7,74\%). Para identificar a reciprocidade das relações estabelecidas foi considerado que um indivíduo que indicou ter aprendido com um determinado ator foi "ensinado por esse ator".

Os processos de aprendizagem por meio dos quais os conteúdos foram transacionados na rede Fundamentação foram: material (22), não especificado (14), apropriação (7), ensinar (7), atividade (3), sugestão / indução (2), convivência (1) e feedback (1). Nenhum dos entrevistados mencionou ocorrências em que o conteúdo tivesse sido transacionado por meio dos processos observação ou supervisão.
Esta rede apresenta uma configuração em que um ator (no caso, ENT2) se destaca mais do que todos os outros. ENT2 está diretamente conectada a 15 dos 21 atores dessa rede. É quem mais aprendeu e ensinou em quantidade de relações e de conteúdos transacionados. ENT2 ensina a 10 e aprende de 7 atores. Dos 57 conteúdos agrupados nessa categoria, ENT2 aprendeu 27 e ensinou 18. Isso significa que 45 dos 57 conteúdos identificados para a rede Fundamentação são transacionados nas relações que ENT2 estabelece diretamente com outros atores. Pode-se dizer que sem a presença de ENT2 - aprendendo ou ensinando - a rede de aprendizagem onde se transacionam conteúdos do tipo Fundamentação deixaria de existir na configuração tal qual foi identificada.

Um ator que se destaca nos dois sentidos das relações estabelecidas entre os atores da rede é alguém que, ao mesmo tempo em que é quem mais precisa ou se interessa pelo aprendizado relativo à categoria, é também a pessoa de referência na organização a respeito do conteúdo transacionado. As falas de ENT2

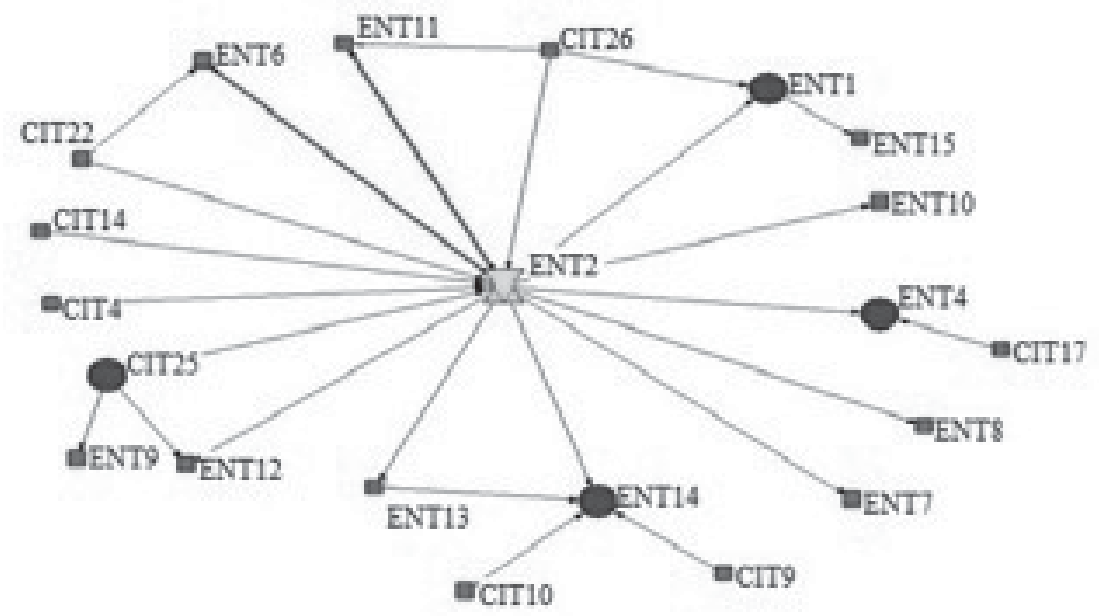

LEGENDA

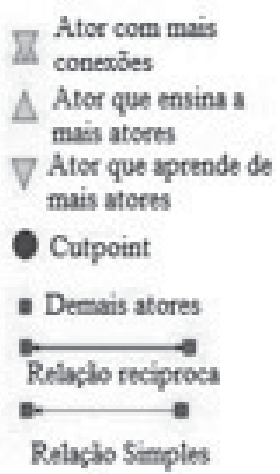

Figura 1: Rede de aprendizagem Fundamentação

Fonte: Elaborado pelos autores deste artigo 
$e$ a respeito dela, dão a entender que é exatamente o seu grande interesse pelo tema que faz com que assuma esse papel e seja reconhecida como tal. Esse mesmo interesse leva ENT2 a fomentar a demanda existente na organização por aprendizados relacionados à rede Fundamentação, contribuindo com a circulação do que já está estabelecido, mas também trazendo elementos novos que reorganizam e renovam os conteúdos transacionados. Ao se analisar a configuração da rede percebe-se que ENT2 é estruturalmente o ator mais influente e que há um grande fluxo de relações e conteúdos transacionados nas duas direções (entrada e saída), o que possivelmente significa que os conteúdos transacionados no conjunto da rede não são estáticos, tendendo a se transformar no tempo.

ENT2 é uma das fundadoras da ONG estudada. Desempenha funções relacionadas à organização, consolidação e disseminação de princípios metodológicos que permeiam tanto as atividades finalísticas quanto os processos das áreas-meio e foi apontada pelos entrevistados como uma referência tanto interna quanto externa (outras pessoas e instituições que se relacionam com a ONG) no que se refere aos conceitos e práticas desenvolvidos na ONG. As cinco fundadoras envolvidas ativamente no dia a dia da organização (dentre elas ENT2) têm a mesma formação acadêmica e apresentavam, quando da fundação da ONG, um percurso profissional semelhante. A especialização de ENT2 ocorreu à medida que na própria organização se refinaram conceitos, valores e metodologias, apontados por todos os entrevistados como o grande diferencial e a identidade da organização. Os entrevistados foram unânimes em afirmar que é esperado de quem trabalhe na organização que compreenda e reproduza os comportamentos relacionados a esse diferencial.

Tendo isso em vista, não é de surpreender que, após a análise dos dados, não foi possível atribuir aos atores que aprenderam ou ensinaram conteúdos da categoria Fundamentação um perfil específico; eles não estão concentrados em alguma área ou gerência nem desempenham algum tipo de atividade específica.

Os atores que aprendem com ENT2 são colegas envolvidos em atividades-fim secundárias (que não as oficinas de criação de produtos midiáticos) (ENT7), em atividades-meio (ENT12); são também membros envolvidos nas atividades-fim (ENT4, 8, 10, 13 e 14) - que vivenciam diariamente, ao planejar e executar ações, as práticas e os conceitos que caracterizam o conteúdo aprendido nessa rede - e colegas fundadores com perfil mais prático (ENT1) que buscam na cofundadora referenciais teóricos que lhe sustentem as decisões metodológicas tomadas para o desenvolvimento dos projetos.

ENT2 busca saberes para consolidar a identidade da organização em colegas relacionados com o meio acadêmico (CIT4, CIT14) e colegas de outros campos de conhecimento que acabaram por se envolver com atividades relacionadas ao domínio da organização estudada (CIT26, CIT22).

As duas relações recíprocas se dão por razões diferentes: ENT11 é outra fundadora da ONG, interlocutora de ENT2 e parceira na definição de quais perspectivas deve se apropriar, como fazê-lo e como transformar tais escolhas em procedimentos da organização. Já ENT6 é um egresso de um dos projetos desenvolvidos pela organização no passado, que acabou por ser agregado ao quadro de colaboradores $e$ cuja percepção sobre o impacto das atividades ajudou a corroborar ou refutar hipóteses quanto à efetividade de práticas que supostamente traduziam os conceitos de base da organização. Apesar da importância a ele atribuída por ENT2, o relato de ENT6 sobre o que aprendeu assemelha-se à de qualquer um de seus pares que não desfrutam de tal relação de reciprocidade.

Os cutpoints ENT4 e ENT14 que aprendem com os edges $^{8}$ que conectam às redes CIT9, CIT10 e CIT17 não trazem nenhuma contribuição à mesma uma vez que não ensinam ninguém da rede central. Por sua vez, os cutpoints ENT1 e CIT25, que ensinam aos edges que conectam às redes ENT15 e ENT9; também não levam o conteúdo transacionado para além das fronteiras da organização porque seus edges são membros de menor destaque, que têm nos atores que lhe ensinam (membros fundadores da organização) sua referência setorial para os conteúdos dessa categoria (ENT1 é superior direto de ENT15 e CIT25 é superior direto de ENT9).

\subsubsection{Rede de Aprendizagem - Comportamento para o Trabalho}

A rede Comportamento, apresentada na Figura 2, é a maior das redes de aprendizagem, tanto em quantidade de relações efetivas (100) quanto em quantidade de conteúdos transacionados (168-29\% 
do total). Participam dela 33 atores, aí incluídos os 16 entrevistados. Possui uma distância geodésica média de 2,47 , e diâmetro 5 , acima da média das outras redes identificadas $(2,12$ e 3,9). Apresenta densidade alta $(9,5 \%)$.

Os processos de aprendizagem por meio dos quais os conteúdos são transacionados na rede Comportamento foram: observação (43), convivência (36), atividade (26), feedback (20), não especificado (13), supervisão (12), apropriação (9) e sugestão / indução (9). Nenhum dos entrevistados mencionou ocorrências em que o conteúdo tivesse sido transacionado por meio dos processos "ensinar" ou "material".

Quem ensina a mais atores é ENT1 (11 atores), seguida de ENT11 (8). ENT2, ENT13 e CIT25 ensinam, cada um a 7 atores. ENT1 e CIT25 foram os atores que mais ensinaram em quantidade de conteúdos de aprendizagem (21 e 18, respectivamente), seguidos de ENT11 e ENT13 (13 e 11 conteúdos, respectivamente). Todas as contagens relativas à quantidade de atores a que os atores se conectaram (entre 6 e 13), à quantidade de atores com quem aprendem ( 5 a 9) e à quantidade de conteúdos (7 a 14), apresentaram escores altos. Dentre os entrevistados, quem se conecta a menos atores é ENT16 (5) e três atores apresentam a menor quantidade de conteúdos aprendidos: ENT9, ENT13 e ENT14 (7 conteúdos cada). Esses escores de valores mínimos por si só são altos, resultando em médias igualmente altas: quantidade média de atores a que cada ator se conecta: 8,44 ; quantidade média de atores que ensinam a cada ator: 6,25; quantidade média de conteúdo aprendido por ator participante da pesquisa: 10,5 .

Os cutpoints existentes têm relevância diferenciada: 1) os que se conectam a apenas um ator são edges que citam aprendizados ocorridos na relação com atores externos à rede; 2) a saída dos atores mais centrais à rede, ENT2 e 9, teria como consequência a redução de conteúdos transacionados, porém não levaria ao isolamento de parte da rede em decorrência da alta conectividade da rede.

Os conteúdos transacionados na rede Comportamento formam um padrão institucional implícito, o do perfil do profissional cujo comportamento é positivamente valorado pela cultura organizacional. A alta conectividade dessa rede sugere que o conjunto de características que forma esse perfil é largamente difundido pela organização. A ONG, que na época da pesquisa tinha reconhecimento internacional $e$ na qual trabalhavam - somando-se quadro fixo e temporário - dezenas de profissionais, começou com um grupo pequeno do qual alguns remanescentes continuam em constante contato com a organização. Quatro desses fundadores participam ativamente do dia a dia da organização atuando em cargos de direção, compondo o comitê gestor e servindo de referência - em vários aspectos - para os demais membros ENT1, ENT2, ENT11 e CIT25. Após anos de convivência e intensos debates a respeito de valores e comportamentos adequados ao desenvolvimento dos trabalhos, as
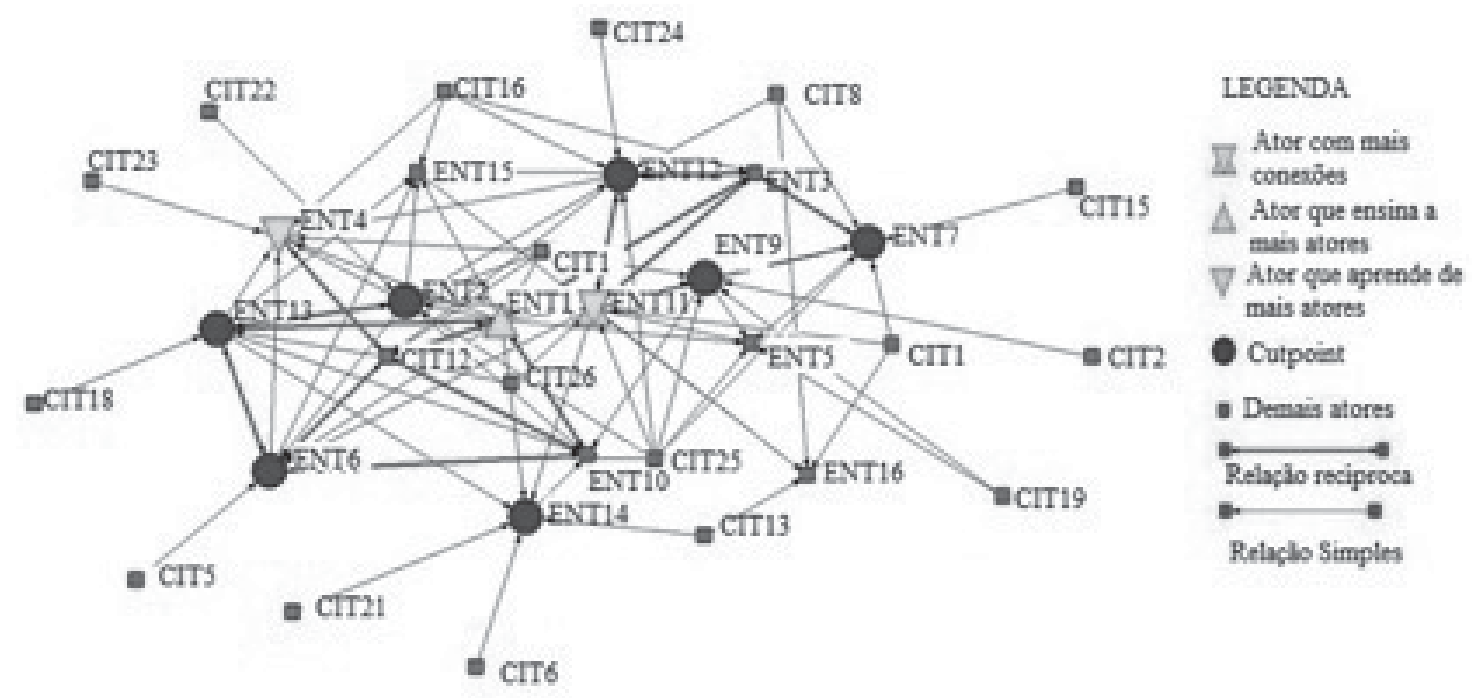

Figura 2: Rede de aprendizagem Comportamento

Fonte: Elaborado pelos autores deste artigo 
fundadoras desenvolveram uma série de postulados, alguns enunciados, outros não. A escolha de quem será convidado a trabalhar na ONG passa pela compatibilidade demonstrada com essas atitudes básicas - e outras delas desdobradas - e que, espera-se, devem moldar as escolhas e decisões dos membros em relação a situações de trabalho. Todos os treze entrevistados que não compõem o comitê gestor relataram aprendizados com essas quatro fundadoras em atividade na ONG, sendo que onze relataram aprender conteúdos da rede Comportamento com mais de uma delas.

As três fundadoras entrevistadas ENT1, ENT2 e ENT11 também relataram aprendizados nesta rede, o que dá um status especial aos atores que lhes ensinam. Nove atores ensinaram às fundadoras conteúdos da rede Comportamento (CIT1, 17, 22, 26 e ENT3, 8, 10, 12, 13).

ENT1 (sócia-fundadora) é quem mais ensina na rede Comportamento, seja em quantidade de atores (11), seja em conteúdos (21).

Os conteúdos aprendidos por ENT1 junto a ENT3, 8, 10, 13 e CIT17, de um modo geral são diferentes dos conteúdos ensinados, o que corrobora resultados de Haythornthwaite (2006) quanto a características de conteúdos transacionados em relações recíprocas. Apenas o modo de se relacionar com outros foi um conteúdo tanto aprendido como ensinado.

Um dos conteúdos aprendidos, relatados por ENT1, ilustra resultado semelhante ao apontado por Poell et al. (2000), Marsick et al. (2008) e Marsick (2009), de que o ambiente e o contexto influenciam o aprendizado e a atuação na organização: ENT8 atua na realização de oficinas de áudio e vídeo e é também um multiartista (música, vídeo, grafite, poesia) que viveu uma experiência de trabalho anterior com regras muito rígidas, que lhe causou grande sofrimento psíquico. Tendo encontrado liberdade na ONG para estabelecer seus processos de trabalho, sua sensibilidade de artista aflorou, expressando-se na criatividade com que lida e encontra soluções para as situações cotidianas.

ENT11 (sócia-fundadora) é a segunda que ensina a mais atores na rede Comportamento (8) e a terceira em quantidade de conteúdos ensinados (13, ficando atrás apenas de ENT1 e CIT25). Entre os conteúdos ensinados por ENT11 incluem-se: como comportar-se no ambiente de trabalho; comunicação (comunicar-se com os outros, falar do trabalho, passar recado); conhe- cer e respeitar o seu próprio ritmo de trabalho; construir relacionamento com mais diálogo com superior direto; disponibilidade para com o colega; dizer não a demandas que violentam sua maneira de produzir; equilibrar trabalho e vida pessoal; organização pessoal para lidar com múltiplas demandas; postura profissional (tratar as pessoas com fineza e educação); responsabilidade com as tarefas; sentidos do trabalho em equipe - aprender a dividir ônus e bônus.

ENT11 aprende conteúdos de CIT1 e 26 e ENT3 e 12. A relação estabelecida com CIT1 (gerente de um projeto patrocinado por uma grande empresa) é importante, pois ilustra a permeabilidade existente entre os ambientes intraorganizacional e extraorganizacional, em que todas as características aprendidas contribuíram para a atuação como diretora de projetos, uma vez que constantemente precisa lidar com os patrocinadores dos projetos. ENT11 atribuiu à atitude de CIT26 uma postura profissional que, segundo ENT11, faltava de uma maneira geral à cultura organizacional: equilibrar trabalho e vida pessoal. Cabe salientar o quanto é paradoxal tal postura de ENT11 uma vez que alguém na posição dela, fundadora, diretora e sócia da ONG, em tese defenderia que as pessoas dessem o máximo de si para a instituição. Mas essa sua preocupação em preservar os projetos e a vida pessoal frente às demandas sem hora e vez da instituição encontrou eco na organização tendo aparecido em várias entrevistas, onde o despertar para esse olhar foi relatado como um aprendizado atribuído a CIT26. Esta situação ilustra o processo de aprendizado pautado na reflexão e a escolha do indivíduo quanto ao que incorporar a sua ação em termos de conteúdo aprendido. (POELL et al., 2000)

Os outros conteúdos aprendidos por ENT11 foram relativos a realizar o trabalho com afetividade e querer sempre realizar o trabalho com qualidade (ENT3) e a como conjugar o envolvimento com os valores de uma organização cujo negócio é promover ações sociais e o pragmatismo necessário ao desempenho de tarefas administrativas (ENT12).

ENT2 (sócia-fundadora) é a terceira que ensina a mais atores na rede Comportamento (7, ficando atrás de ENT1 e ENT11). Não se destaca tanto em quantidade de conteúdos ensinados (9, ficando em sétimo lugar), mas tem grande peso na definição de atitudes valoradas pela instituição. Entre os conteúdos 
ensinados por ENT2 incluem-se: atitude positiva no ambiente de trabalho; comunicação; convivência para o trabalho; estabelecer diálogo e transitar nos vários níveis da instituição; excelência na execução de tarefas; maleabilidade na adoção de pontos de vista; ouvir o colega de trabalho, assumir posicionamentos a partir da valorização das vivências/pontos de vista do outro; quebrar um preconceito que se tem em relação a um colega de trabalho.

ENT2 aprende conteúdos de CIT17 e 22 e de ENT13 e CIT22. Os aprendizados vindos de atores externos CIT17 e 22 dizem respeito ao modo como esses profissionais desenvolvem o trabalho, agregando elementos de outros campos do conhecimento, experimentando, criando e inovando o desempenho profissional no dia a dia, assim como a atitude positiva no ambiente de trabalho, e são semelhantes aos relatados por ENT11.

O aprendizado com ENT13 difere-se do conteúdo aprendido com ENT1, por não estar com ele envolvido nos processos de trabalho cotidiano, o que a leva a estabelecer uma relação de aprendizado baseada em outras demandas. Essa diferença na natureza das relações também fica clara ao se perceber que os processos pelos quais ENT2 aprende com ENT13 diferem daqueles pelos quais ENT1 aprende. No caso de ENT1, os processos são "ensinar" e "feedback", enquanto que ENT2 aprende por "observação".

Sair do senso comum na execução das tarefas de trabalho é parte da rotina da ONG, a ponto de ser esperado de seus membros que incorporem de maneira criativa à sua rotina de trabalho a experimentação $e$ a pesquisa. Aprende-se, por exemplo, a: estabelecer interseções entre vários campos de significados; inovar nas atividades trazendo elementos de outros campos do conhecimento; desenvolver um domínio retórico e poético; executar as atividades de maneira solta, leve, criativa; experimentar sistematicamente formas alternativas de execução das tarefas; ter por hábito pesquisar elementos para enriquecer o trabalho; desenvolver uma visão alternativa $e$ individual das coisas que se apresentam no dia a dia, ressignificando as tarefas e desafios cotidianos em busca de soluções ainda não utilizadas.

Finalmente, outro subgrupo de aprendizados incluídos na categoria Comportamento para o Trabalho trata de comportamentos marcados por aspectos relacionados nas entrevistas à palavra "ética". Envolve aprender o que os entrevistados consideram uma postura ética e política, diante do trabalho e do fazer, ao se primar pelo tratamento igualitário, lidando com todos de maneira a se sentirem iguais na equipe, independente do tempo de casa ou do cargo, garantindo transparência e honestidade na disponibilização do fluxo de informação. O aprendizado de uma conduta profissional norteada por princípios éticos, que determinam decisões e comportamentos, também diz respeito a ser transparente em relação aos erros cometidos, independentemente do cargo que ocupa, ajudando e dando abertura para ser ajudado a superar dificuldades e falhas.

\subsubsection{Rede de Aprendizagem - Relacionamento com Atores Externos}

A rede Relacionamento, apresentada na Figura 3 , é a quinta rede de aprendizagem em quantidade de relações (28 relações efetivas) e de conteúdos transacionados (39). Participam dela 21 atores, sendo que destes, 14 integram o grupo dos 16 entrevistados. Possui uma distância geodésica média de 2,23, valor próximo da média das outras redes $(2,12)$. Seu diâmetro e densidade (3 e 7,0\%, respectivamente) também ficam próximos da média das outras redes (3,9 e 7,74\%), ainda que um pouco abaixo.

Os processos de aprendizagem por meio dos quais os conteúdos são transacionados na rede Relacionamento, foram: observação (16), ensinar (8), supervisão (4), apropriação (3), atividade (2), convivência (2), não especificado (2), feedback (1), sugestão/ indução (1). Nenhum dos entrevistados mencionou ocorrências em que o conteúdo tivesse sido transacionado por meio do processo Material.

A rede apresenta uma configuração onde um ator se destaca mais que todos os outros: ENT11. Este ator é quem se conecta ao maior número de atores (9), e quem mais ensina, tanto em número de atores (7) quanto de conteúdos (13). Os atores que citaram ENT11 aprenderam por meio de cinco processos diferentes: apropriação, ensinar, observação, sugestão / indução, supervisão.

ENT11 é um cutpoint de primeira relevância uma vez que é o único ator a conectar dois clusters diferentes, de doze e oito atores. Os dois grupos não aparen- 


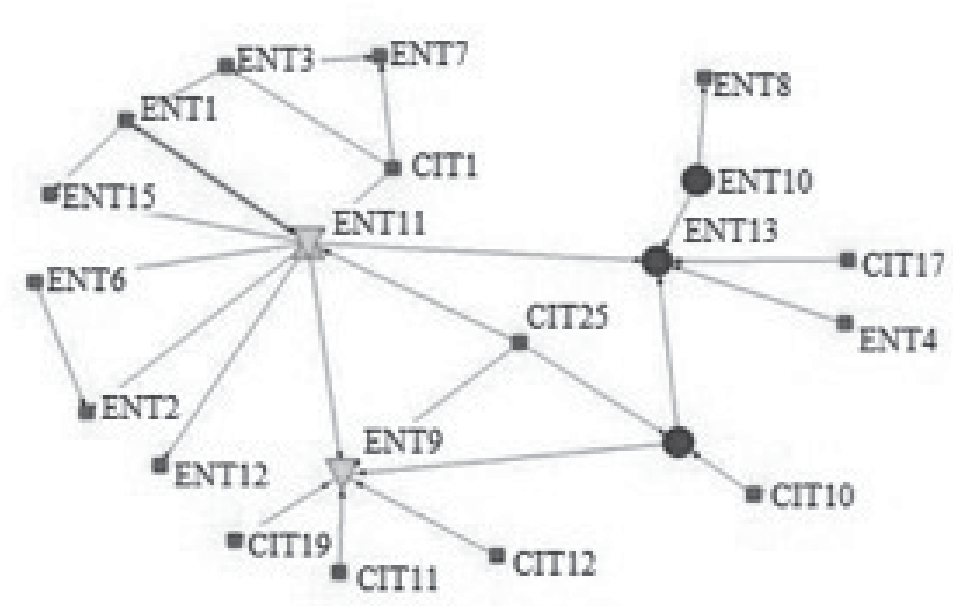

LEGENDA

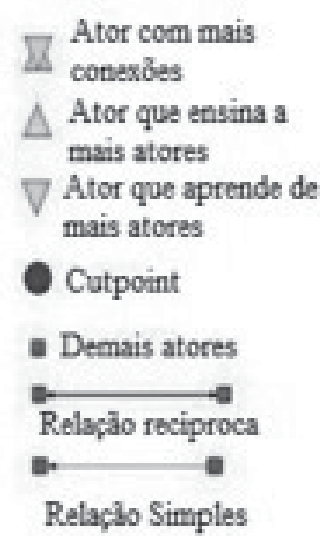

Nota. O ator ENT11 também é cutpoint, porém está representado na figura apenas como "ator com mais conexões"

Figura 3: Rede de aprendizagem Relacionamento

Fonte: Elaborado pelos autores deste artigo

tam ser formados por atores com traços comuns, porém por meio de ENT11 ocorre a transação de conteúdos dentro de uma lógica importante para o funcionamento da organização, conforme relatado a seguir.

Os conteúdos que ENT11 aprende ou ensina na rede dizem respeito não só ao relacionamento com financiadores, mas também com outros atores externos necessários à viabilização de um projeto (público-alvo de uma ação e integrantes da comunidade onde um projeto está em execução). Conteúdos citados por executores de atividades finalísticas (por exemplo, decorrentes de relações com fornecedores) não foram citados na entrevista com ENT11 ou nas falas relativas a ela.

O período escolhido como escopo temporal desta pesquisa foi marcado pelo gerenciamento de um projeto que se desdobrava em várias ações, patrocinado por uma empresa de grande porte e extenso escopo territorial, considerada parceira estratégica da ONG. Apesar de CIT1 ser seu subordinado, ENT11 o toma como modelo de comportamento para um profissional do terceiro setor incumbido de relações institucionais. CIT1, por sua reconhecida competência nesse tipo de função, tornou-se visado pelo mercado e acabou aceitando um convite para trabalhar na empresa cujo relacionamento gerenciava. CIT1 enquanto trabalhou na ONG tornou-se muito familiarizado com o ponto de vista desse parceiro estratégico, daí a importância para a organização pesquisada dos conteúdos com ele aprendidos por ENT11, a sua disseminadora na rede de aprendizagem interna. Esse relacionamento é importante não apenas pelo que se aprende sobre um parceiro em especial, mas por ajudar a organização a se familiarizar com o ponto de vista de uma grande empresa que possui um departamento com orçamento direcionado para investimentos sociais: suas demandas, receios, perspectivas e expectativas. Em seu depoimento, ENT11 chegou a dizer que cogitava propor ao comitê gestor da organização a criação de um setor para tratar especificamente da captação de recursos e que seria CIT1 quem ela gostaria que assumisse a responsabilidade por tal área.

CIT25 é um ator que não se destaca na rede Relacionamento, porém é de grande importância para os conteúdos transacionados nessa rede de aprendizagem devido às competências que demonstra na elaboração de projetos. CIT25 e ENT11 são reconhecidos na organização pelo talento para a redação de propostas direcionadas a parceiros financiadores, cada qual com suas características próprias. CIT25 possui vasta rede de relacionamentos junto a empresas e órgãos governamentais que se interessam por patrocinar 
ações que a ONG se especializou em realizar e é uma fonte de aprendizados sobre oportunidades surgidas no segmento de investimentos sociais. Apresenta-se constantemente atualizada sobre em que e como empresas e governos estão investindo em organizações não governamentais e contribui no relacionamento com ENT11 devido à sua objetividade e pragmatismo na análise das possibilidades reais relacionadas às oportunidades surgidas junto a possíveis patrocinadores. Pode-se supor que CIT25, caso tivesse sido entrevistada, também relataria aprender com ENT11 conteúdos relacionados à capacidade produtiva da organização e à percepção de oportunidades afinada com as capacidades da equipe.

A relação recíproca ENT11 $\leftrightarrow$ ENT1 é a única existente na rede de aprendizagem Relacionamento. ENT11 e ENT1 são membros fundadores da organização, as duas atuando na área de projetos, uma com um nível de abordagem mais estratégico, a outra mais operacional. São sócias envolvidas ativamente no dia a dia da organização, cujo percurso lhes levou a especializações diferentes que se complementam. Em um determinado momento da história da organização as duas atuaram juntas desenvolvendo as mesmas funções e à medida que a quantidade de projetos executados simultaneamente aumentou, cada uma desenvolveu uma especialização específica.

O conteúdo relatado até o momento corrobora resultados dos estudos desenvolvidos por Van Der Krogt (1995) e Poell et al. (2000) quanto ao papel ativo dos indivíduos nos processos de aprendizagem e a interrelação com processos e estruturas.

De acordo com nomenclatura proposta por Ferd Van Der Krogt (POELL et al., 2000), as políticas de aprendizagem de uma organização tratam de atividades que definem o que e como os membros da organização deveriam aprender.

Não foi identificada a existência de atividades específicas promovidas pela direção da organização que atendam aos quesitos de um procedimento de planejamento linear das atividades de aprendizagem a serem desempenhadas pelos integrantes da organização. Porém, como relatado nas redes Fundamentação e Comportamentos para o trabalho, o modo como as líderes da ONG conduziam as atividades no período da pesquisa atendem ao proposto na Teoria de Rede de Aprendizagem quanto a estruturas e processos disponibilizados, havendo, pelas ações desenvolvidas, um direcionamento mais amplo das redes de aprendizagem. Ou seja, o espaço onde tais políticas são formuladas, na ausência de atividades designadas intencionalmente para tanto, são os próprios processos de aprendizagem por meio dos quais as relações se instauram, criando as redes de aprendizagem. Os conteúdos ali veiculados ampliam visões, criam novas necessidades e questionam os saberes acumulados e disponíveis na organização.

Por exemplo, na rede Fundamentação, as práticas organizacionais são fortemente influenciadas por um conjunto de referenciais teóricos inicialmente selecionados para fundamentar a atividade fim, os quais acabaram por permear toda a organização, marcadamente presente no discurso organizacional e determinando o seu funcionamento como um todo. $\mathrm{O}$ diferencial da organização reside no sucesso das práticas fomentadas a partir dos conteúdos veiculados nessa rede. Para que esse diferencial se sustente e se renove foi incorporado ao cotidiano da organização, desde a sua fundação, atividades formais e informais onde são promovidas discussões, reflexões e teorizações do dia a dia da organização, atividades onde opera a rede Fundamentação e que reforçam sua existência.

Outro exemplo é a rede Comportamento, cujos conteúdos encerram um padrão institucional implícito, o do perfil do profissional cujo comportamento é positivamente valorado pela cultura organizacional. Essa rede é tão significativa que engloba a totalidade dos entrevistados, cada um aprendendo de pelos menos outros cinco colegas os conteúdos ali transacionados. Os membros da organização se deparam cotidianamente com comportamentos considerados exemplares que se multiplicam pelas relações estabelecidas nessa rede. Fazer parte da rede Comportamento leva os membros da organização a criarem ou incorporarem referências a serem seguidas, daí criando demandas de aprendizagem que se renovam à medida que os conteúdos veiculados na rede se transformam.

Uma série de conhecimentos, habilidades e atitudes inicialmente eleitos pelos fundadores para pautarem o funcionamento da organização foram sendo incorporados às redes de aprendizagem que se formaram. O aumento da complexidade da organização trouxe também o aumento da complexidade da configuração da rede social decorrente das relações 
de aprendizagem estabelecidas pelos membros da organização para a realização de suas atividades. As redes de aprendizagem tornaram possível, a todos os seus integrantes, a participação no desenvolvimento das políticas de aprendizagem, uma vez que cada um individualmente é um operador da rede da qual faz parte. Porém sabe-se que a influência que cada ator exerce numa rede não é igual. Os fundadores que se mantém em atividade, vivenciando o dia a dia da organização, continuaram dispondo de autoridade para influenciar mais do que qualquer outro membro, as políticas de aprendizagem. Na ONG essa autoridade foi conferida pelos demais membros da organização, devido ao seu papel na história da organização e às posições que ocupavam.

Os conteúdos transacionados nas diversas redes de aprendizagem operando na organização acabam por criar demandas e prioridades sobre o que aprender e como aprender. Daí, naturalmente e de maneira não programática, surgem reflexões a respeito de necessidades de aprendizagem e competências disponíveis e desejáveis que levam ao desenvolvimento de políticas de aprendizagem. Essas políticas não são definidas a priori e permanecem implícitas, pelo menos do ponto de vista da organização, se instaurando por força de um entendimento comum construído nas redes de aprendizagem.

Para os processos de aprendizagem, por meio dos quais os conteúdos das redes são transacionados, é possível fazer uma associação de que eles têm relação com: 1) a natureza dos conteúdos transacionados; 2) as características e preferências individuais e, ainda, 3) com a inserção dos indivíduos na estrutura organizacional, o que inclui as relações de poder. (VAN DER KROGT, 1995; POELL et al. 2000; MARSICK, 2009)

Os programas de aprendizagem de uma organização são, de acordo com nomenclatura proposta por Ferd Van Der Krogt, oportunidades criadas para a aprendizagem ou a combinação de várias atividades de aprendizagem em programas mais ou menos coerentes (POELL; VAN DER KROGT, 2003). Neste estudo, que focou a aprendizagem informal, é possível apreender que estas ações permeiam toda a ONG, provavelmente em função de suas próprias características.

A Teoria de Redes de Aprendizagem define uma trilha de aprendizagem como um conjunto de atividades de aprendizagem que ao mesmo tempo têm uma coerência entre si e são significativas para o membro da organização (POELL; VAN DER KROGT, 2007). Os dados coletados - conteúdos aprendidos, processos de aprendizagem e com quem ocorreu a aprendizagem permite traçar e identificar essas trilhas, para cada um dos pesquisados, porém, não foi o objetivo deste estudo. Cabe ressaltar, porém, que para a explicitação das trilhas individuais seria preciso colher mais informações a respeito do encadeamento cronológico dos diversos aprendizados e as circunstâncias que eventualmente unem o aprendizado de um ou mais conteúdos (por exemplo, a ocorrência de programas de aprendizagem).

Em relação aos conteúdos é possível identificar que alguns são, de modo geral, semelhantes a qualquer organização (exemplo, comunicação, relacionamento interpessoal, socialização) enquanto outros são específicos e decorrentes das características organizacionais (vide estudo de Haythornthwaite, 2006). Já os processos de aprendizagem (exemplo: reflexão, feedback, material escrito, observação), assim como aspectos do contexto e do ambiente que impactam a aprendizagem são semelhantes ao encontrado na literatura.

\section{Considerações Finais}

O objetivo principal desse trabalho foi identificar redes de aprendizagem em uma organização não governamental, entre 2007 e 2008, caracterizando-as quanto a conteúdos transacionados e processos de aprendizagem, os quais foram alcançados.

Os conteúdos aprendidos nas redes de aprendizagem dizem respeito a: 1) comportamentos associados ao ambiente organizacional (Fundamentação e Visão da organização, Comportamento para o trabalho; Relacionamento com atores externos); 2) conhecimentos e habilidades necessários à realização do trabalho (Técnica; Gestão; Condução de oficina; Projeto); e 3) desenvolvimento individual (Referência pessoal; Artes \& cultura; Estímulo ao próprio desenvolvimento). E os processos de aprendizagem identificados foram: Apropriação, Atividade, Convivência, Ensinar, Feedback, Material, Observação, Sugestão/indução e Supervisão. As redes de aprendizagem identificadas foram analisadas quanto a aspectos estruturais, conteúdos transacionados e processos utilizados. 
Os procedimentos metodológicos deste estudo, com uso de técnicas qualitativas e quantitativas e a associação da análise de redes sociais à Teoria de Rede de Aprendizagem mostraram-se adequados para a compreensão da aprendizagem organizacional na ONG pesquisada. A análise dos gráficos das redes, aliado aos dados qualitativos coletados, permitiu visualizar a aprendizagem como fruto de relações dinâmicas estabelecidas entre diversos atores, em situações delimitadas pelas ações cotidianas e as condições impostas pelo ambiente e o contexto. Adicionalmente, o uso do método de análise de rede permitiu caracterizar as ligações que se estabelecem entre os membros de uma organização e explicar como delas decorre o surgimento de uma intrincada rede de relações interpessoais.

Outra contribuição deste trabalho está na caracterização da aprendizagem em uma organização, cruzando informações relativas aos conteúdos aprendidos com os processos por meio dos quais a aprendizagem aconteceu. Situações de trabalho diferentes despertam interesses e necessidades de aprendizagem diferentes. A depender da natureza do conteúdo que se aprende ou das preferências e características dos indivíduos, certos processos de aprendizagem são mais recorrentes ou funcionam melhor do que outros.

Sugere-se, para fins de pesquisas futuras, a replicação do desenho de pesquisa em outras organizações, para fins de comparação e levantamento de uma quantidade maior de dados que permita inferir relações de causa e efeito na configuração das redes de aprendizagem estudadas.

\section{REFERÊNCIAS}

ARGOTE, L. et al. Knowledge transfer in organizations: learning from the experience of others. Organizational Behavior and Human Decision Processes, New York, USA, v. 82, n. 1, p. 1-8, maio, 2000.

BAILEY, D. E.; BARLEY, S. R. Learning ecologies at work: teaching and learning as everyday activity. Working Paper, Center for Work, Technology and Organizations, Stanford University, 2000.

\section{BOSE, M. Gestão de pessoas no terceiro setor.}

2004. 219f. Dissertação (Mestrado em Administração). Faculdade de Economia, Administração e Contabilidade, Universidade de São Paulo, São Paulo, 2004.

\section{CAMARGO, M. F. et al. Gestão do terceiro setor} no Brasil: estratégias de captação de recursos para organizações sem fins lucrativos. 2. ed. São Paulo: Futura, 2001.

\section{EDWARDS, M.; HULME, D. Non-governmental} organizations - performance and accountability: beyond the magic bullet. London: Save the Children/ Earthscan, 1995.

HAYTHORNTHWAITE, C. Learning and knowledge networks in interdisciplinary collaborations. Journal of the American Society for Information Science and Technology, USA, v. 57, n. 8, p. 1.079-1.092, jun. 2006.

KIM, D. H. The link between individual and organizational learning. Sloan Management Review, Fall, p. 37-50, 1993.

MARSICK, V. J. Toward a unifying framework to support informal learning theory, research and practice. Journal of Workplace Learning, Bradford, England, v. 21, n. 4, p. 265-275, 2009.

MARSICK, V. J. et al. Informal and incidental learning in the workplace. In: SMITH, M. C. and DeFrates-Densch, N. (Ed.). Handbook of Research on Adult Learning and Development, Routledge, New York, NY, 2008.

POELL, R. F. et al. Learning-network theory: organizing the dynamic relationships between learning and work.

Management Learning, London, England, v. 31, n. 1, p. 25-49, 2000.

\section{POELL, R. F. Organizing work-related learning} projects: a network approach. Unpublished doctoral dissertation. University of Nijmegen. Nijmegen: The Netherlands, 1998.

\section{POELL, R. F.; MOORSEL, M. The learning network}

theory: its contribution to our understanding of work based learning projects and learning climate, RadBoud Reposity, Internal Report, 1996. Disponível em: < http:// hdl.handle.net/2066/18558>. Acesso em: 16 mar. 2010.

POELL, R; VAN DER KROGT, F. J. Learning-program creation in work organizations. Human Resource Development Review, Thousand Oaks, USA, v. 2, n. 3, p. 252-272, set. 2003. 
POELL, R. VAN DER KROGT, F. J. The contribution of social networks to individual learning in service organizations. Paper presented at the International Research Conference in The Americas of the Academy of Human Resource Development. Indianapolis, fev.-mar., 2007.

\section{SWIERINGA, J.; WIERDSMAN, A. Becoming a}

learning organization: beyond the learning curve. Wokingham: Addison-Wesley, 1992.

TEODÓSIO, A. S. S.; VENEROSO, R. S.; PENA, R. P. M. Nada de novo no front: caminhos e descaminhos do voluntariado e do capital social como formas de ativismo comunitário. In: Pimenta, S. M.; SARAIVA, L. A. S.; CORRÊA, M. L. (Org.). Terceiro setor: dilemas e polêmicas. São Paulo: Saraiva, 2006.

TORO, J. B. O papel do terceiro setor em sociedades de baixa participação. In: IOSCHPE, E. B. $3^{\circ}$ setor desenvolvimento social sustentado. 2 . ed. São Paulo, Paz e Terra, 2000.

VAN DER KROGT, F. J. Leren in netwerken: Veelzijdig organiseren van leernetwerken met het oog op humaniteit en arbeidsrelevantie Learning in networks: the manyfaceted job of organizing learning networks with a view to humanity and work relevance. Utrecht: Lemma, 1995.

VAN DER KROGT, F. J. The learning network theory: The tensions between learning systems and work systems in organizations. Human Resource Development Quarterly, v. 9, n. 2, p. 157-178, 1998.

\section{WASSERMAN, S.; FAUST, K. Social Network}

Analysis: methods and applications. Cambridge: Cambridge University Press, 1994.

\section{NOTAS}

1 Os dados que poderiam identificar a ONG pesquisada foram omitidos para preservar o anonimato da organização.

2 Quantidade de pessoas entrevistadas ou citadas nas entrevistas, integrantes da rede. (WASSERMAN; FAUST, 1994, p. 17)

3 Média de todas as distâncias geodésicas entre os atores da rede. A distância geodésica é o tamanho do menor caminho entre dois atores. (WASSERMAN; FAUST, 1994, p. 110)

4 Distância entre os dois atores da rede que se encontram mais distantes um do outro. (WASSERMAN; FAUST, 1994, p. 112)

5 Em função da quantidade de atores de uma rede, há um número máximo potencial de relações que esses atores podem estabelecer entre si. A densidade é a proporção de relações efetivamente estabelecidas frente à quantidade de relações potenciais que a rede permitiria.

(WASSERMAN; FAUST, 1994, p. 101-102)

6 Um cutpoint é um ator que, uma vez removido da rede, faz com que a rede remanescente passe a se constituir de dois subgrupos de atores, sem nenhuma conexão entre si. (WASSERMAN; FAUST, 1994, p. 112)

7 Relação entre dois atores em que o conteúdo da rede é transacionado nas duas direções. No caso da rede de aprendizagem, os dois atores aprendem um com o outro, mutuamente. (WASSERMAN; FAUST, 1994, p.124)

8 Ator conectado a apenas um ator. 